\title{
A Cone Beam Computed Tomography Study Among Dental Residents Based on a Questionnaire
}

\author{
Alexandra Mihaela Stoica, Assistant Lecturer, DMD \\ Monica Monea, Associate Prof., DMD, PhD \\ Dragos Dan Sita, Assistant Lecturer, DMD
}

Department of Odontology and Oral Pathology, Faculty of Dental Medicine,

University of Medicine and Pharmacy Tirgu Mures, Romania

Mircea Buruian, Prof., $M D, P h D$

Department of Radiology, Faculty of Medicine,

University of Medicine and Pharmacy Tirgu Mures, Romania

doi: 10.19044/esj.2016.v12n36p32 URL:http://dx.doi.org/10.19044/esj.2016.v12n36p32

Abstract

Objectives: The aim of our study was to analyse the utility of the CBCT systems among the dental residents form the Dental University of TarguMures.

Material and methods: We conducted an anonymous survey using a questionnaire that included 11 questions. All the 55 participants from all dental specialties studied at the Dental University Center Targu-Mures. The completed questionnaires were collected the results were evaluated and statistically analyzed using chi-square test.

Results: Most residents have learnt about the CBCT during the university studied by participating at different radio-imagistic courses outside the curriculum. Only 33 (60\%) residents recommend daily a CBCT for supporting their diagnosis most of them being oral surgeons and 7 (12.72\%) of them occasionally recommend between 1 and 5 CBCTs a month.

Conclusions: The CBCT system used as an imagistic evaluation in all dental specialties is essential and the advantages can be found in the accuracy of establishing a correct diagnosis, creating a treatment plan and results evaluation.

Keywords: Cone Beam Computed Tomography, radiation, Radiology.

\section{Introduction}

In the late 21st century it become well-known that the CBCT (Cone Beam Computed Tomography) system is essential in the radiological evaluation in many dental cases. It has a radiation dose lower than the CT 
(Computed Tomography) scan but it is comparable with the radiation dose obtained in a series of retro alveolar x-rays (radiography) for the whole dental situation or an OPT (panoramic x-ray) (Falk H et al 1986, Shao MY et al 2009). This new imagistic system is ergonomical, it has a reduced size and offers the possibility of obtaining multiple radiographic images at a high resolution for the whole craniofacial anatomical structures (J Endod 2015).

The two-dimensional (2D) image interpretation offered by conventional radiography (retro alveolar radiography, panoramic radiography, bite-wing), it can be difficult and sometimes erroneous. The correct dental diagnosis can be misled by the superimposition of the anatomical structures. These obstacles can be overcome by using the CBCT system for the radioimagistic assessment in most dental cases (Matherne RP et al 2008, Shekhar $\mathrm{V}$ et al 2013).

CBCT is a technology that uses a modern and recent X-ray source on a rotating arm and a detector which is fixed. During rotation is achieved a high number of sequential images between 150 and 600 for the investigated anatomical structure. CT technique uses X-rays in a different way than CBCT and it needs more sequence images for the 3D rebuild which has a lower quality then CBCT's 3D reconstruction. CBCT system performs only a single rotation sequence which is sufficient in collecting data for reconstructing the final 3D image compared to 2D images like retro alveolar $\mathrm{X}$-rays that needs a separate scan every time (Patel S 2012, Durack C et al 2012).

The CBCT system was initially dedicated for angiography, but due to the great information and all data offered for all anatomical structures and the possibility of the maxillofacial reconstruction it was introduces in dentistry. Nowadays, the CBCT technology is rapidly advancing using higher resolution and allowing its use in implantology, orthodontics, dental surgery, periodontology, endodontics, maxillofacial surgery not least in oral pathology (Li G 2013, Arnheiter C et al 2006).

\section{Material and methods}

To have access to the dental resident doctor's information about CBCT we conducted an anonymous survey using a questionnaire. All the dental residents studied at the Dental University Center from Targu-Mures and agreed to participate.

The study protocol was reviewed by the Ethics Committee of the University of Medicine and Pharmacy form Targu-Mures. A total of 55 dental residents from all specialties, endodontics, surgery, prosthetics, periodontics and orthodontics participated in the study and answered the questionnaire which included 11 questions. The completed questionnaires were collected the results were evaluated and statistically analyzed using chi-square test. 


\section{Results}

From all 55 dentists who agreed to participate to our study $15(27.27 \%)$ are endodontists, $16(29.09 \%)$ are surgeons, 11 (20\%) are orthodontists, 7 (12.72\%) prosthetists and 6 (10.9) periodontists (fig.1) and only 28 of them (50.90\%) have learnt about the CBCT during the university studied by participating at different imagistic courses outside the curriculum. Only 33 $(60 \%)$ residents use the CBCT of supporting the diagnosis daily recommending more than $10 \mathrm{CBCTs}$ a month and $7(12.72 \%)$ of them occasionally recommending between 1 and 5 CBCTs a month.

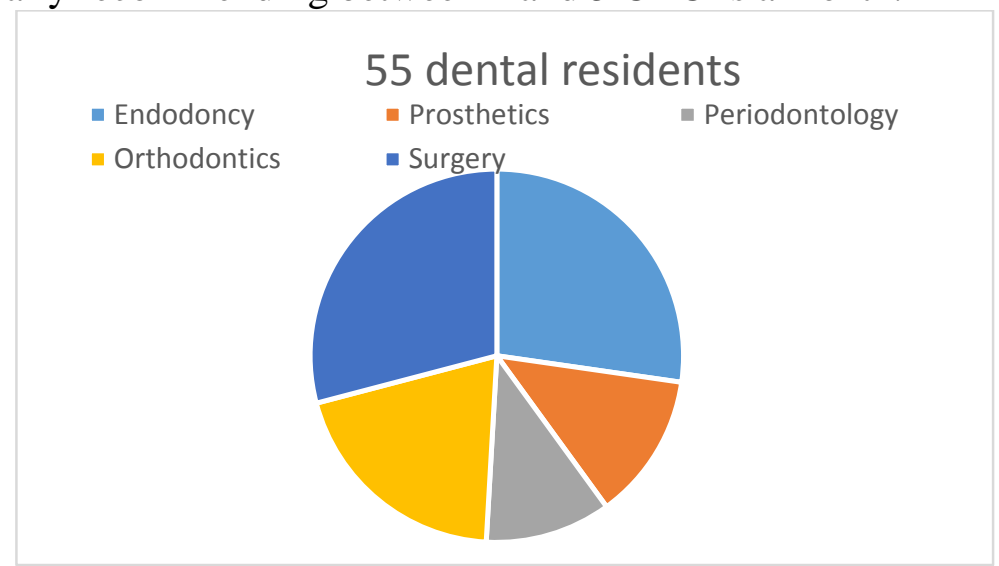

Fig.1 Dental specialties of all participants to the study.

Although the use of the CBCT is low despite the quantum of data offered but 2D imagistic is highly used among all young dental residents (fig.2).

\begin{tabular}{|c|c|c|c|c|c|}
\hline & OPT & $\begin{array}{c}\text { Retro alveolar } \\
\text { x-ray }\end{array}$ & Cephalogram & $\begin{array}{c}\text { Bite-wing } \\
\text { x-ray }\end{array}$ & TMJ x-ray \\
\hline Endodontists & 5 & $>10$ & 0 & 5 & 0 \\
\hline Prosthetists & $>10$ & 5 & 0 & $>10$ & 0 \\
\hline Periodontists & $>10$ & $>10$ & 0 & 5 & 0 \\
\hline Orthodontists & $>10$ & $>10$ & $>10$ & 5 & 0 \\
\hline Dental surgeons & $>10$ & $>10$ & 0 & 5 & $>10$ \\
\hline
\end{tabular}

Fig.2 Number of conventional $\mathrm{x}$-ray used a month by all dental residents.

In the assessment of post treatment situation CBCT is used by 16 residents $(29.09 \%)$, and occasionally by $11(20 \%)$ and only the dental surgeons interpret the images alone, the rest rely on the radiological specialist interpretation and rarely they have the chance of comparing CBCT images with conventional 2D x-rays, between 1 to 5 in 20\% cases. Endodontists frequently use $\mathrm{CBCT}$ in persistent apical pathology, retreating incorrect root canal fillings, surgeons for third molar extraction and implantology and periodontists for the evaluation of the alveolar bone resorption. They all consider a CBCT course during your university studies very useful. 


\section{Discussion}

Radiology has experienced a remarkable evolution and important changes in recent years with the appearance of numerous advanced ways of imaging that convert the technically two-dimensional images into tridimensional images of life (Ludlow JB 2008). These new imagistic systems offer the possibility of an exact interpretation of the medical pathology and give enough information for an accurate diagnosis (Moshiri M et al 2007).

CBCT finds its applications in almost all fields of dentistry and is one of the most widely accepted imaging systems in the present (Parashar V et al 2012, Shetty SR et al 2016). Due to its recent discovery as an imaging modality, little is known about the interpretation of images using different software. The ability to develop and to improve the software is unlimited due and advanced level of knowledge in terms of understanding how the CBCT works (Dula K et al 2014, Alamri HM et al 2012). Therefore, the current study was conducted to assess knowledge of CBCT and its use among young resident doctors who graduated from the Dental University form Targu-Mures.

In our study we found that most of the respondents felt a need for new courses about CBCT scanner and the need for help in the diagnosis and treatment planning for the future. Moreover, a CBCT scanner can be helpful in educational institutions for training practice. We also found that most of the residents have not used or recommended CBCT for diagnostic purposes and only a few interpret the images independent. This can be attributed to unavailability of a CBCT's curriculum during the university studies because of the recent introduced imagistic evaluation. Most of the physicians included in our study felt they needed a scanner CBCT in the university and they suggested the importance of becoming familiar with handling scanner and interpret multiple images, rather than to have only theoretical knowledge.

It was observed in our study that almost all resident doctors felt it needed a of using CBCT in their daily practice, and they participated at different postgraduate courses about CBCT. Limited use of CBCT as shown in our study in order to track nerve fracture cases, implant placement, pathology sinus cysts and tumors, pathologies of the temporomandibular joint could be attributed to the lack of CBCT systems in our university. In this study we found that most of the participants were unsure about radiation exposure compared to other imaging modalities. Moreover, most respondents do not indicate a CBCT more than 10 per month and they prefer the conventional $\mathrm{x}$ rays and rarely use $\mathrm{CBCT}$ for the assessment of the post treatment situation. They use the interpretation offered by the radiology specialist, and rarely encountered the situation of comparing the CBCT images with retro alveolar or panoramic x-rays.

In Endodontics all treatments are based on correct identification of the exact tooth structure, roots and root canals, and 2D radiography often provide 
inaccurate information because of superimposition of the anatomical structures and hiding vital details (Mozzo P et al 1998, Brian JN 2007). These details are essential in treating cases like obliterated root canals and the success depends on being able to access the apex. We support the conclusions of the authors that the CBCT is superior for detecting and evaluating all pathological lesions that can be discovered in an early stage and a higher rate of perfect treatment (Kamburoglu K et al 2011, Parashar V et al 2012).

\section{Conclusion}

The poor knowledge about the benefits of the CBCT system because of insufficient academic curriculum, among young doctors and residents, has reduced its practical application. By increasing the number of continuing education programs, the CBCT applicability can be sustained and may improve general dental practice for all specialties.

Including the study of the CBCT imaging as a potential imagistic investigation in dental education is essential and the advantage can be found in the accuracy and reliability of treatment planning using 3D imaging and in the results evaluation.

\section{References:}

1. Falk H, Ericson S, Hugoson A. The effects of periodontal treatment on mucous membrane thickening in the maxillary sinus. J Clin Periodontol. 1986;13:217-22.

2. Shao MY, Huang P, Cheng R, Hu T. Interleukin-6 polymorphisms modify the risk of periodontitis: A systematic review and metaanalysis. J Zhejiang UnivSci B. 2009;10:920-7.

3. J Endod. Periodontitis and clinical symptoms in Endodontic Patients using Cone-beam Computed Tomography and Periapical Radiographs. 2015, Nov. 41 (11): 1824-9. doi: 10.1016/j.joen. 2015. 06. 004, Epub. 2015 sep5.

4. Matherne RP, Angelopoulos C, Kulilid JK, Tira D. Use of cone-beam computed tomography to identify root canal systems in vitro. J Endod, 2008: 34: 87-89.

5. Shekhar V, Shashikala K. Cone beam computed tomography evaluation of the diagnosis, treatment planning and long-term followup of large periapicallesions treated by endodontic surgery. Two case reports. Case Report in Dentistry, 2013, Article ID 564392, doi.org/10.1155/ 2013/ 564392. 
6. Patel S. New dimensions in Endodontic imaging. Part 2. Cone-beam computed tomography. Int Endod J, 2009, 42 (6): 463-475.

7. Durack C, Patel S. Cone beam computed tomography in endodontics. Braz Dent J, 2012; 23 (3): 179-191.

8. Li G. Patient radiation dose and protection from cone-beam computed tomography. Imaging Sci Dent.2013;43:63-69.

9. Arnheiter C, Scarfe WC, Farman AG. Trends in maxillofacial conebeam computed tomography usage.Oral Radiol. 2006;22:80-85.

10. Ludlow JB. Dosimetry of KODAK 9000 3D Small FOV CBCT and Panoramic Unit. University of North Carolina, School of Dentistry; Chapel Hill, NC, USA: 2008.

11. Moshiri M, Scarfe WC, Hilgers ML, et al. Accuracy of linear measurements from imaging plate and lateral cephalometric images derived from cone-beam computed tomography. Am J Orthod Dentofacial Orthop. 2007;132:550-60.

12. Parashar V, Whaites E, Monsour P, et al. Cone beam computed tomography in dental education: A survey of U.S., U.K., and Australian Dental Schools. Journal of Dental Education. 2012;76:1443-47.

13. Shetty SR, Castelino RL, Babu SG, et al. Knowledge and attitude of dentists towards cone beam computed tomography in mangalore - a questionnaire survey. Austin J Radiol. 2015;2(2):1016.

14. Dula K, Bornstein MM, Buser D, et al. SADMFR guidelines for the use of cone-beam computed tomography/digital volume tomography a consensus workshop organized by the Swiss Association of Dentomaxillofacial Radiology. Swiss Dental Journal. 2014;124:117083.

15. Alamri HM, Sadrameli M, Alshalhoob MA, et al. Applications of CBCT in dental practice: A review of the literature. Gen Dent. 2012;60(5):390-400.

16. Mozzo P, Procacci C, Tacconi A, Martini PT, Andreis IA. A new volumetric CT machine for dental imaging based on the cone-beam technique: Preliminary results. Eur Radiol 1998; 8: 1558-1564.

17. Brian JN, Williamson GF. Digital radiography in dentistry: A survey of Indiana dentists. Dentomaxillofac Radiol 2007; 36: 18-23. 
18. Kamburoglu K, Kursun S, ZZ Akarslan ZZ. Dental students' knowledge and attitudes towards cone beam computed tomography in Turkey. Dentomaxillofac Radiol 2011; 40: 439-443.

19. Parashar V, Whaites E, Monsour P, Chaudhry J, Geist JR. Cone beam computed tomography in dental education: A Survey of U.S., U.K., and Australian Dental Schools. J Dent Educ 2012; 76: 1443-1447.

\section{Questionnaire}

1.What is your specialty as a dentist?
a. Dental surgery
b. Periodontology
c. Endodontics
d. Orthodontics
e. Prosthetic

2. Did you study the CBCT system as a radio-imagistic evaluation in dentistry during your university studies?
a. Yes
b. No

3. Do you use CBCT in you daily practice for establishing the diagnosis?
a. Yes
b. No
c. Occasionally

4. How many indications for CBCT a month do you recommend?
a. 0
b. $1-5$
c. $6-10$
d. $>10$

5. How many conventional X-rays a month do you use (panoramic, bite-wing, retro alveolar periapical X-ray, lateral cephalogram)?
a. 0
b. 1-5
c. $6-10$
d. $>10$

6. On an average, how many times did you have to compare CBCT with the conventional X-rays?
a. 0
b. $1-5$
c. $6-10$
d. $>10$

7. Do you use CBCT for the assessment of the post treatment situation?
a. Yes
b. No
c. Occasionally

8. Do you interpret the CBCT images alone?

a. Yes b. No, I rely on the radiological specialist interpretation

9. Please write the most frequent case in which you indicate the CBCT.

10. Please indicate with " $x$ " mark the correct dose of radiation in these different types of X-rays:

\begin{tabular}{|c|l|l|l|l|l|}
\hline X-Ray type & \multicolumn{5}{|c|}{ Radiation dose } \\
\hline & $5-7 \mu \mathrm{S}$ & $3-11 \mu \mathrm{S}$ & $30-80 \mu \mathrm{S}$ & $20-30 \mu \mathrm{S}$ & $18-135 \mu \mathrm{S}$ \\
\hline Bite Wing & & & & & \\
\hline Retro alveolar periapical X-ray & & & & & \\
\hline TMJ X-ray & & & & & \\
\hline CBCT & & & & & \\
\hline Panoramic X-ray (OPT) & & & & & \\
\hline Lateral/frontal cephalogram & & & & & \\
\hline
\end{tabular}

11. Do you consider a CBCT course during your university studies useful?
a. Yes
b. No 